\title{
Phonocardiographic, radiological, and haemodynamic correlation in atrial septal defect
}

\author{
Allan Rees, Odette Farru, and Raul Rodriguez \\ From the Cardiac Unit, Department of Pediatrics, Roberto del Rio Hospital, University of \\ Chile and National Health Service of Chile; and the Institute of Radiology, fose foaquin \\ Aguirre Hospital, University of Chile
}

Haemodynamic auscultatory, phonocardiographic, and haemodynamic radiological correlations were studied in $5 I$ patients with proven atrial septal defect.

A good correlation exists between the degree of left-to-right shunt and auscultatory and phonocardiographic parameters, especially for a tricuspid rumble, tricuspid opening snap, and delay of the tricuspid component of the first heart sound.

$A$ poor correlation exists between the degree of left-to-right shunt and the severity of radiological pulmonary hypervascularity. Therefore, when discordance is present between the auscultatory and radiological findings we believe the auscultatory criteria are more valuable for estimating the degree of shunt.

The clinical findings in atrial septal defect in general depend on the magnitude of the leftto-right shunt. As studies have shown (Nadas, I963), when a tricuspid diastolic murmur exists the pulmonary flow is twice the systemic flow, and when radiological examination reveals increased pulmonary flow, the increase exceeds the systemic flow by about two times (Kaplan, I968; Neill, I968).

In many instances, however, the auscultatory phonocardiographic findings and the radiological findings fail to correlate, in particular when a tricuspid diastolic murmur indicates an atrial septal defect with an appreciable left-to-right shunt, but radiological findings point to only a normal or slightly increased pulmonary flow.

Because of such discrepancies, we decided to study patients with atrial septal defects, to learn whether certain auscultatory phonocardiographic parameters correlated with the haemodynamic state, and whether the degree of radiological pulmonary hypervascularity paralleled haemodynamic studies. Our purpose was to try to establish which of those parameters corresponded best with the leftto-right shunt, since the decision to undertake surgical repair depends on the magnitude of the shunt.

Received 8 October 1971.

\section{Subjects and methods}

Fifty-one patients with atrial septal defect were studied. All were proved by cardiac catheterization and 35 confirmed by operation; 33 of the patients had phonocardiographic studies. Their ages varied between 3 and 16 years (average 9.5 years); 34 were girls and 17 boys. None of them had pulmonary hypertension. From the magnitude of the pulmonary flow, as determined by haemodynamic studies, the patients were divided into three different groups:

Group I Those with a pulmonary systemic flow ratio $(\mathrm{Qp} / \mathrm{Qs})$ of 2 or more (35 patients).

Group II: Those with a Qp/Qs between I.5 and 2 (I2 patients).

Group III: Those with a $\mathrm{Qp} / \mathrm{Qs}$ of less than I.5 (4 patients).

Chest $x$-rays were analysed with special attention given to the characteristics of the pulmonary vascularity. The films were classified into four categories: normal pulmonary vascularity, slight hypervascularity $(+)$, moderate hypervascularity $(++)$, and severe hypervascularity $(t++)$. Three radiologists studied the films without knowing the diagnoses. In all cases at least two of the radiologists evaluated the pulmonary vascularity equally.

We determined the presence and characteristics of a tricuspid diastolic murmur by auscultation.

With the phonocardiogram, we analysed the 
characteristics of the tricuspid diastolic murmur, the opening snap when present, the degree of splitting of the second sound and the intensity of the pulmonary component, the characteristics of the first tricuspid component, and the eventual registration of a pulmonary click. Each of these parameters was correlated with the magnitude of the left-to-right shunt, as expressed by the Qp/Qs ratio. In our analysis of the results we applied the statistical method with the assistance of the Biomathematics Department of the University of Chile, Medical School.

\section{Results}

All the patients of Group I (35) had a tricuspid diastolic murmur; in Group II (I2) Io had this murmur, 2 did not; in Group III (4) none had it (Table I).

Of the 33 patients studied phonocardiographically (Table 2 ), 30 presented a tricuspid diastolic murmur (detected through auscultation and phonocardiogram). The $\bar{x}$ of $Q p / Q s$ in these patients was $2 \cdot 75$. In the patients without the murmur (3), it was only I.53. The statistical difference between these two groups is significant.

The tricuspid diastolic murmur was recorded early, at $0.04^{\prime \prime}$ to $0.06^{\prime \prime}$ after $\mathrm{P2}$ and was of medium to high frequency. No correlation was found between $Q p / Q s$ and the time of inscription of this murmur.

In 15 of the 33 patients (Table 3 ) an opening tricuspid snap was registered; however, in none of these was the snap detected by auscultation because of its low intensity. The $\bar{x}$ of $Q p / Q s$ in these 15 patients was 3.38, and in the 18 patients in whom a tricuspid opening snap was not recorded the $\bar{x}$ of $Q p / Q s$ was only $\mathrm{I} \cdot 93$. Here, too, there was a significant statistical difference between the two groups. The time of registration of this snap in relation to $\mathrm{P}_{2}$ was between $0.03^{\prime \prime}$ and $0.05^{\prime \prime}$. No correlation was detected between that time of inscription and the $Q p / Q s$.

The degree of splitting of the second sound varied between $0.04^{\prime \prime}$ and $0.07^{\prime \prime}$ and in general remained fixed during inspiration and expiration, with respiratory variation in some patients of only $0.0 I^{\prime \prime}$. No correlation was found between the degree of splitting of the second sound and the magnitude of the leftto-right shunt.

As to the intensity of $\mathrm{P}_{2}$ (Table 4), we found it normal in 18 patients with $a \bar{x}$ of $\mathrm{Qp} / \mathrm{Qs}$ of 2, and slightly or moderately accentuated in 15 patients with a $\bar{x}$ of $Q p / Q s$ of 3.8. A significant difference between these two groups was evident.

We were unable to detect a pulmonary
TABLE I Haemodynamic auscultatory

correlation in $5 I$ cases of atrial septal defect in relation to tricuspid diastolic murmur

\begin{tabular}{lll}
\hline Group I (35 cases) & Group II (I2 cases) & Group III (4 cases) \\
\hline $\begin{array}{l}\text { Qp/Qs 2 or more } \\
\text { All with tricuspid diastolic } \\
\text { murmur }\end{array}$ & $\begin{array}{c}\mathrm{Qp} / \mathrm{Qs} \mathrm{I} \cdot 5-2 \\
\text { Io with tricuspid diastolic } \\
\text { murmur }\end{array}$ & $\begin{array}{c}\mathrm{Qp} / \mathrm{Qs} \text { under I.5 } \\
\text { None with tricuspid } \\
\text { diastolic murmur }\end{array}$ \\
\hline
\end{tabular}

Qp/Qs, pulmonary systemic flow ratio.

click in any of the patients, but in 33 phonocardiographically studied, there was a splitting of the first heart sound in the fourth intercostal space. It fluctuated between 0.02 " and $0.04^{\prime \prime}$ (mean $0.036^{\prime \prime}$ ) with a tricuspid component which was between $0.02^{\prime \prime}$ and $0.10^{\prime \prime}$ from the beginning of QRS: the longer the registration of the tricuspid component of the first sound was delayed and the louder it was, the easier it became to confuse it with a click by auscultation. A linear association (Table 5) existed between the time of inscription of the tricuspid component of the first sound and the $\bar{x}$ of $Q p / Q s:$ a longer delay in the inscription indicated a greater flow. No such linear association existed between the intensity of the tricuspid component and the $\bar{x}$ of $Q p / Q s$ (Table 6).

The study of the radiological-haemodynamic correlation (Table 7) revealed the following: when radiological studies disclosed appreciable pulmonary hypervascularity, the $\bar{x}$ of $Q p / Q s$ was above 2 in 100 per cent of the patients. When the increase of pulmonary vascularity was moderate, the $\bar{x}$ of Qp/Qs was above 2 in 68 per cent of the patients; in 22 per cent of the patients the $\bar{x}$ of $Q p / Q$ s fluctuated between $I \cdot 5$ and 2, and in ro per cent it was under 1.5 . In the patients with a slight increase of pulmonary vascularity, 57 per cent had a Qp/Qs of 2 or more and 43 per cent of $I .5$ to 2 . In the two patients with a normal pulmonary vascularity, the Qp/Qs was less than I.5.

TABLE 2 Haemodynamic phonocardiographic correlation in 33 cases of atrial septal defect in relation to tricuspid diastolic murmur

\begin{tabular}{lc}
\hline $\begin{array}{l}\text { With tricuspid diastolic } \\
\text { murmur (30 cases) }\end{array}$ & $\begin{array}{l}\text { Without tricuspid diastolic } \\
\text { murmur (3 cases) }\end{array}$ \\
\hline$\overline{\mathrm{x}} \mathrm{Qp} / \mathrm{Qs} 2.75$ & $\overline{\mathrm{x}} \mathrm{Qp} / \mathrm{Qs} \mathrm{r} \cdot 53$ \\
$\mathrm{~s} 0.91 \mathrm{I}$ & $\mathrm{s} 0.15$ \\
\hline
\end{tabular}

The difference between both groups is statistically significant $(P<0.01)$.

$\mathrm{Qp} / \mathrm{Qs}$, pulmonary systemic flow ratio. 
TABLE 3 Haemodynamic phonocardiographic correlation in 33 cases of atrial septal defect in relation to tricuspid opening snap

\begin{tabular}{|c|c|}
\hline $\begin{array}{l}\text { With tricuspid opening } \\
\text { snap (I5 cases) }\end{array}$ & $\begin{array}{l}\text { Without tricuspid opening } \\
\text { snap ( } 18 \text { cases) }\end{array}$ \\
\hline $\begin{array}{cr}\bar{x} \text { Qp/Qs } & 3.38 \\
\text { s } & 1.06\end{array}$ & $\begin{array}{cc}\overline{\mathbf{x}} \mathrm{Qp} / \mathrm{Qs} & \mathbf{I} \cdot 93 \\
\mathrm{~s} & 0.3^{8}\end{array}$ \\
\hline
\end{tabular}

The difference between both groups is statistically significant $(t=5.414$ and $P<0.01)$.

$\mathrm{Qp} / \mathrm{Q}$, pulmonary systemic flow ratio.

\section{Discussion}

The decision to perform surgical repair of an atrial septal defect depends on the magnitude of the left-to-right shunt as measured by cardiac catheterization. In some surgical centres (Nadas, 1963; Kaplan, 1968; Neill, 1968; Flege, Helmsworth, and Kaplan, 1963) closure of an atrial septal defect is advised if the pulmonary-systemic flow ratio exceeds 2: I. In other centres repair of the defect is made even when the flow ratios are $1 \cdot 5: 1$ (Kaplan, 1968; Neill, 1968; Schrire and Vogelpoel, 1964) since the mortality of the operation is so low.

Although in more than 90 per cent of the patients the diagnosis of secundum atrial septal defect is made clinically and therefore the results of cardiac catheterization are not unexpected, it has been the practice in most clinics to confirm the diagnosis preoperatively. But in some cardio-surgical centres (Flege et al., 1963) an operation can be performed without prior cardiac catheterization, basing judgement on a clinical estimation of the magnitude of the shunt. Consequently, it is important to make a good clinical haemodynamic correlation. For that we consider auscultation and the degree of radiological pulmonary vascularity to be important parameters, though less studied than haemodynamic electrocardiographic correlations,

TABLE 4 Haemodynamic phonocardiographic correlation in 33 cases of atrial septal defect in relation to intensity of $\mathrm{P}_{2}$

\begin{tabular}{ll}
\hline Normal P2 & $\begin{array}{l}\text { P2 slightly or moderately increased } \\
(15 \text { cases })\end{array}$ \\
\hline$\overline{\mathrm{x}} \mathrm{Qp} / \mathrm{Qs} 2$ & $\overline{\mathrm{x}} \mathrm{Qp} / \mathrm{Qs}{ }_{3} \cdot 18$
\end{tabular}

The difference between both groups is statistically significant $(t=3.13$ and $P<0.01)$.

$\mathrm{P2}$, pulmonary component of the second sound.

$\mathrm{Qp} / \mathrm{Qs}$, pulmonary systemic flow ratio.
TABLE 5 Haemodynamic phonocardiographic correlation in 33 cases of atrial septal defect: delay of tricuspid component of Ist heart sound with respect to $Q R S$

\begin{tabular}{ll}
\hline Tricuspid component of Ist heart sound & $\bar{x} Q p / Q s$ \\
\hline $0.07^{\prime \prime}$ (4 cases) & $1 \cdot 82$ \\
$0.08^{\prime \prime}$ (I9 cases) & $2 \cdot 33$ \\
$0.09^{\prime \prime}$ (5 cases) & $2 \cdot 85$ \\
$0.10^{\prime \prime}$ (5 cases) & 3.96 \\
\hline
\end{tabular}

A linear correlation between the delay of the tricuspid component of the Ist heart sound and the average of $Q p / Q s$ ratio exist with a coefficient $r=0.6 \quad(n=33)$ $(\alpha=0.01)$.

Qp/Qs, pulmonary systemic flow ratio.

which have been frequently reported (Zaver and Nadas, 1965; Barber, Magidson, and Wood, 1950; Burch and DePasquale, 1959; Dreifus et al., 1959; Martins de Oliveira and Zimmerman, 1958; Toscano-Barbosa, Brandenburg, and Swan, 1958; Walker et al., 1956; Dushane et al., 1960).

From the present study it becomes apparent that an excellent correlation exists between the magnitude of the pulmonary flow and the auscultatory findings and phonocardiography, especially with the tricuspid rumble, the tricuspid opening snap, the delay of the tricuspid component of the first heart sound, and the loudness of the pulmonary component of the second heart sound. The correlation allows the clinician accurately to predict the amount of the shunt. Consequently, surgical treatment can be undertaken without previous haemodynamic studies, sparing the cost of medical and paramedical personnel, equipment, and admission to hospital.

It is generally agreed that the external diastolic murmur heard in atrial septal defect is caused by the increased flow across the tricuspid valve (relative tricuspid stenosis), and

TABLE 6 Haemodynamic phonocardiographic correlation in 33 cases of atrial septal defect: intensity of tricuspid component of Ist heart sound

\begin{tabular}{lcl}
\hline Tricuspid component of Ist heart sound & $\bar{x} Q p / Q s$ \\
\hline Normal or slightly increased (I3 cases) & $2 \cdot 06$ \\
Moderately increased & (8 cases) & $2 \cdot 24$ \\
Much increased & (12 cases) & 3.42 \\
\hline
\end{tabular}

No linear correlation between intensity of the tricuspid component of the Ist heart sound and the average of $Q p / Q$ s ratio was demonstrable $(r=0.246$ not statistically different from the significant level $\alpha=0.01$ ). $\mathrm{Qp} / \mathrm{Qs}$, pulmonary systemic flow ratio. 
that is detected in the inflow tract of the right ventricle in the intracardiac phonocardiogram (Kaplan, 1968; Neill, 1968; Flege et al., 1963; Zaver and Nadas, 1965; Barritt, Davies, and Jacob, I965; Wennevold, I966; Liu and Jacono, 1958; Feruglio and Sreenivasan, 1959; Lewis et al., 1959; Eisenberg and Hultgren, 1959; Leatham and Gray, 1956; Gasul, Arcilla, and Lev, 1966). In atrial septal defect, however, an early diastolic murmur can also exist, which originates in the interatrial septal defect (Somerville and Resnekov, 1965) though this murmur is not heard by external auscultation (Wennevold, 1966; Gasul et al., 1966).

From the present study, correlating haemodynamics with auscultatory and phonocardiographic findings, we could show that a very good correlation exists between the amount of pulmonary flow and the presence of a tricuspid rumble. This murmur always points to a significant shunt, and therefore to the necessity of surgical treatment. Nevertheless, no correlation exists between the time of inscription of the murmur and the amount of pulmonary flow. The murmur is early in diastole with medium or high frequency vibrations.

The presence of a tricuspid opening snap always indicates a considerable shunt, but no correlation exists between the time of registration of this opening snap and the magnitude of the pulmonary flow.

The degree of splitting of the second heart sound has no correlation with the amount of the pulmonary flow, but there is a certain correlation between intensity of $\mathrm{P}_{2}$ and the amount of the shunt (in cases without pulmonary hypertension): $\mathbf{P 2}_{2}$ is slightly or moderately accentuated when the $\mathrm{Qp} / \mathrm{Qs}$ exceeds 3. Some authors (Gasul et al., 1966) explain an accentuated $\mathrm{P}_{2}$ in atrial septal defect without pulmonary hypertension by the amount of the pulmonary flow together with the proximity of the pulmonary artery to the anterior wall of the thorax and the energy of contraction of the right ventricle.

None of our patients had pulmonary hypertension; that is understandable because their average was 9.5 years. It is well known (Evans, Rowe, and Keith, I96I) that pulmonary hypertension in childhood occurs in only 5 per cent of the patients with atrial septal defects, but between 20 and 40 years the percentage rises to I4 per cent (Craig and Selzer, 1968). The absence of pulmonary hypertension in our material explains why we heard no systolic clicks. Such an early systolic ejection click is seldom present in an uncomplicated atrial septal defect (Nadas, I963; Gasul et al., 1966; Dimond and Benchimol, 1959).
TABLE 7 Haemodynamic radiological correlation in $5 I$ cases of atrial septal defect

\begin{tabular}{|c|c|c|c|c|}
\hline & $\begin{array}{l}\text { Hypervascu- } \\
\text { larity }+++\end{array}$ & $\begin{array}{l}\text { Hypervascu- } \\
\text { larity + + }\end{array}$ & $\begin{array}{l}\text { Hypervascu- } \\
\text { larity + }\end{array}$ & $\begin{array}{l}\text { Normal } \\
\text { vascularity }\end{array}$ \\
\hline No. of cases & 13 & 22 & I4 & 2 \\
\hline $\begin{array}{l}\text { Per cent } Q p / Q s>2 \\
\text { Per cent } Q p / Q s I \cdot 5-2 \\
\text { Per cent } Q p / Q s<I \cdot 5\end{array}$ & $\begin{array}{r}100 \\
0 \\
0\end{array}$ & $\begin{array}{l}68 \\
22 \\
10\end{array}$ & $\begin{array}{r}57 \\
43 \\
0\end{array}$ & $\begin{array}{r}0 \\
0 \\
100\end{array}$ \\
\hline
\end{tabular}

$Q p / Q s$, pulmonary systemic flow ratio.

A splitting of the first heart sound, however, was identified in all of our patients, the interval from mitral or tricuspid closure ranging from $0.02^{\prime \prime}$ to $0.04^{\prime \prime}$ (mean $0.036^{\prime \prime}$ ). It was a true splitting of the first heart sound and not an early ejection click: it was louder in the fourth left sternal border, it was not modified by respiration, and its second component was always inscribed before the $\mathrm{E}$ point of the right apex cardiogram.

The registration of a split first heart sound is frequent in atrial septal defects (Barritt et al., 1965; Leatham and Gray, 1956). On auscultation, however, such a split sound usually is inaudible. According to Eisenberg and Hultgren (1959) there is a pathological splitting of the first heart sound in atrial septal defects: they recorded it from $0.02^{\prime \prime}$ to $0.05^{\prime \prime}$ with a mean value of $0.038^{\prime \prime}$, the normal value ranging from 0.02 " to $0.04^{\prime \prime}$ with a mean value of $0.028^{\prime \prime}$. The difference in mean values between the two groups is statistically significant. Splitting of the first sound is due to a delayed tricuspid component (Eisenberg and Hultgren, 1959; Leatham and Gray, 1956; Dimond and Benchimol, 1959). In our patients, the delay of the tricuspid component fluctuated from $0.07^{\prime \prime}$ and $0.10^{\prime \prime}$ with respect to QRS, and a linear association was present between delay of inscription of the tricuspid component and the mean values of $Q p / Q s$. With a delay of the tricuspid component of $0 \cdot 10^{\prime \prime}$ or greater, the pulmonary flow was always three or more times the systemic flow.

According to some authors (Eisenberg and Hultgren, 1959) the tricuspid component is retarded because the onset of right ventricular contraction is slightly delayed. Other investigators (Barritt et al., 1965; Leatham and Gray, 1956) report that no such delay in the onset of right ventricular contraction occurs, except when a complete right bundle-branch block is present.

It might be expected in atrial septal defect that the closure of the tricuspid valve would be delayed because the increased flow across 
the valve in diastole would thrust the leaflets deep into the ventricle. When ventricular systole occurs, more time is required for the leaflets to become stretched and tense than if they had moved towards a position of partial closure just before ventricular systole. The mechanism of delay would be similar to that of the mitral component of the first heart sound in left-to-right shunts, in which the shunt flow passes through the mitral valve: ductus, ventricular septal defect, Blalock anastomosis (Karnegis and Wang, 1963), and atrial septal defects with right-to-left shunt (Karnegis and Wang, 1966). This explanation agrees with the good correlation found between the delay of tricuspid component and amount of pulmonary flow.

The intensity of the delayed tricuspid component shows no linear association with the amount of pulmonary flow, though there seems to be a tendency for a louder tricuspid component with greater pulmonary flows.

With respect to the haemodynamic radiological correlation, to our knowledge no double-blind study has been made of the least amount of left-to-right shunt detectable as an increase in vascularity. Evaluation of pulmonary vascularity is not yet amenable to measurement and contains an element of guess-work. Nevertheless, the method used here to evaluate the degree of increased pulmonary vascularity allowed us to believe the evaluations were correct.

It has been reported (Kaplan, 1968; Neill, 1968) that an increase in the pulmonary vascularity can be detected when the pulmonary flow exceeds two or more times the systemic flow, and that experienced observers can usually reveal such changes when the pulmonary systemic flow ratio is only $x \cdot 4$. Our haemodynamic-radiological correlation confirms the statement by Kaplan and by Neill, since 100 per cent of our patients with more than a 2:I flow show pulmonary vascular changes in $x$-rays as did the majority with a flow less than 2: I. The degree of hypervascularity however correlated poorly with the amount of the shunt, since in patients with shunts greater than $2: I$ the pulmonary vascularity as judged from radiographs was found to vary greatly, being either slightly, moderately, or severely increased. On the other hand, the pulmonary vascularity proved to be normal in some patients with a flow less than $1 \cdot 5: 1$. Correlation in individual patients often proved to be poor. According to Zaver and Nadas (1965), radiological studies in atrial septal defects may reveal either normal vascularity, or slight, moderate, or hypervascularity with very different degrees of pulmonary flow.
For that reason, if a discordance between auscultation and degree of pulmonary vascularity exists, we believe one should follow the auscultatory phonocardiographic criteria for estimating the degree of shunt.

\section{References}

Barber, J. M., Magidson, O., and Wood, P. (1950). Atrial septal defect, with special reference to the electrocardiogram, the pulmonary artery pressure and the second heart sound. British Heart fournal, 12, 277.

Barritt, D. W., Davies, D. H., and Jacob, G. (1965). Heart sounds and pressures in atrial septal defect. British Heart fournal, 27, 90.

Burch, G. E., and DePasquale, N. (1959). The electrocardiogram and ventricular gradient in atrial septal defect. American Heart fournal, 58, 190.

Craig, R. J., and Selzer, A. (1968). Natural history and prognosis of atrial septal defect. Circulation, 37, 805.

Dimond, E. G., and Benchimol, A. (1959). Phonocardiography in atrial septal defect: correlation between hemodynamic and phonocardiographic findings. American Heart fournal, 58, 343.

Dreifus, L. S., Bender, S., Goldberg, H., and Downing, D. F. (1959). The electrocardiogram in atrial septal defect. Diseases of the Chest, 36, 521 .

Dushane, J. W., Weidman, W. H., Brandenburg, R. O., and Kirklin, J. W. (I960). Differentiation of interatrial communications by clinical methods: ostium secundum, ostium primum, common atrium, and total anomalous pulmonary venous connection. Circulation, 21, 363.

Eisenberg, R., and Hultgren, H. N. (1959). Phonocardiographic features of atrial septal defect. Circulation, 20, 490.

Evans, J. R., Rowe, R. D., and Keith, J. D. (I96I). The clinical diagnosis of atrial septal defect in children. American fournal of Medicine, 30, 345.

Feruglio, G. A., and Sreenivasan, A. (1959). Intracardiac phonocardiogram in thirty cases of atrial septal defect. Circulation, 20, 1087.

Flege, J. B., Jr., Helmsworth, J. A., and Kaplan, S. (1963). Surgical management of atrial septal defects. American Surgeon, 29, 868.

Gasul, B. M., Arcilla, R. A., and Lev, M. (1966). Heart Disease in Children, pp. 368 and 369. J. B. Lippincott, Philadelphia.

Kaplan, S. (1968). Atrial septal defects. In Paediatric Cardiology, pp. 379 and 392 . Ed. by H. Watson. Lloyd-Luke, London.

Karnegis, J. N., and Wang, Y. (1963). The Q-I interval of the phonocardiogram in patients with ventricular septal defect, patent ductus arteriosus and Blalock anastomosis. American fournal of Cardiology, II, 452.

Karnegis, J. N., and Wang, Y. (1966). Q-I interval of the phonocardiogram in patients with atrial septal defect. British Heart fournal, 28, 240.

Leatham, A., and Gray, I. (1956). Auscultatory and phonocardiographic signs of atrial septal defect. British Heart fournal, 18, 193.

Lewis, D. H., Deitz, G. W., Wallace, J. D., and Brown, J. R. (I959). Intracardiac phonocardiography. Progress in Cardiovascular Diseases, 2, 85.

Liu, C. K., and Jacono, A. (1958). Phonocardiography in atrial septal defect. American fournal of Cardiology, 2, 714. 
Martins de Oliveira, J., and Zimmerman, H. A. (1958). The electrocardiogram in interatrial septal defects and its correlation with hemodynamics. American Heart fournal, 55, 369.

Nadas, A. S. (1963). Pediatric Cardiology, 2nd ed., pp. 372, 373, and 383. W. B. Saunders, Philadelphia and London.

Neill, C. A. (1968). Radiology of the heart. In Paediatric Cardiology, p. 165. Ed. by H. Watson. Lloyd-Luke, London.

Schrire, V., and Vogelpoel, L. (1964). Atrial septal defect. American Heart fournal, 68, 263.

Somerville, J., and Resnekov, L. (1965). The origin of an immediate diastolic murmur in atrioventricular defects. Circulation, 32, 797.

Toscano-Barbosa, E., Brandenburg, R. O., and Swan, H. J. C. (1958). Atrial septal defect: the electrocardiogram and its hemodynamic correlation in 100 proved cases. American fournal of Cardiology, 2, 698.
Walker, W. J., Mattingly, T. W., Pöllock, B. E., Carmichael, D. B., Inmon, T. W., and Forrester, R. H. (1956). Electrocardiographic and hemodynamic correlation in atrial septal defect. American Heart fournal, 52, 547.

Wennevold, A. (1966). The diastolic murmur of atrial septal defects as detected by intracardiac phonocardiography. Circulation, 34, 132.

Zaver, A. G., and Nadas, A. S. (1965). Atrial septal defect - secundum type. Circulation, 32, Suppl. 3, 24.

Requests for reprints to Dr. Odette Farru, Universitäts-Kinderklinik (Luisen-Heilanstalt), 6900 Heidelberg-I, Hofmeisterweg I-9, Germany. 